\title{
A disappointing decade of AIDS
}

\author{
Hopes that research would quickly yield a prophylaxis for AIDS, or possibly a cure, appear to be evaporating, \\ together with the belief that infectious disease is historical only.
}

THE organizers of this year's international AIDS conference, arranged for June in Berlin, are fearful that potential participants from elsewhere will be deterred from taking part by news reports of attacks on foreign visitors to Germany. In a statement last week (see page 6), they sought to reassure visitors by referring to the brave stand on xenophobia taken by the federal German president, Dr Richard von Weizsäcker, among others. The hope seems to be that there will be 15,000 people in Berlin in June, as there have been at earlier annual conferences in this series (which alternates between a US venue and one elsewhere).

In reality, this year may be different for reasons other than participants' fear of being attacked. One obvious difficulty is the general impression that the annual AIDS conferences are no longer a preferred means of describing the results of new research, but instead are occasions of a more theatrical character. To the extent that they throw together researchers in the field and those who suffer from AIDS, or at least are infected by the human immunodeficiency virus (HIV), they are a vehicle by which the patients may express their frustration, even anger, that research has done so little for them.

This year, there may well be even more of that than previously. To put it mildly, AIDS research has lapsed into a kind of silence. That does not mean that nothing is being done, of course. On the contrary, there is a substantial army of people at work on the characterization of the strains of HIV responsible for individual infections, while the detailed parameters of different epidemiological models are being steadily if slowly refined. But it seems a long time since Mrs Margaret Heckler, then the Secretary of Health and Human Services in the US administration, was talking eagerly of a vaccine against HIV. In fact, that was nine years ago next June. It is not surprising that the field is rife with disappointment.

For what it is worth, this is far from being a unique occasion when the high promise of some field of research has turned out to be less attainable than serious people believed. In 1958, for example, Nature published a clutch of papers from the UK Atomic Energy Research Establishment at Harwell purporting to have demonstrated that thermonuclear fusion (not the cold kind) could be brought about in a laboratory apparatus (181, 217-233; 1958). Only shrewd Lyman Spitzer of Princeton expressed doubts on the subject (181, 221-222; 1958). Most of those involved were already sketching the designs of the working fusion reactors they saw being thrown up around the world. Now, nearly half a century later, a great deal has been learned about hot plasmas and their confinement, but nobody would now dare say whether thermonuclear reactors will ever be feasible in the sense of being economic.

AIDS seems now to be in the same case. The obvious prophylactic, a vaccine, must be intrinsically more difficult to develop than Heckler and her advisers could have imagined. How do you set about destroying all $\mathrm{T}$ cells harbouring the retrovirus HIV, perhaps as complementary DNA integrated within the genome, without causing an immune deficiency as damaging as that of AIDS itself? If, on the other hand, the pathogenesis of AIDS resembles that of an autoimmune disease, which is plausible enough, it is prudent to remember that there are no systemic prophylactics for other candidate autoimmune diseases.

Quite how a vaccine, if there were one, would be used is also perplexing. Would it be administered to all children before puberty, or to the groups known to be most at risk, and what would be made of it in the poor countries of Africa, where the incidence of HIV infection is alarming, but where health budgets are usually too small for even diagnostic tests for HIV infection to be affordable?

The search for drugs effective in the treatment of patients with AIDS has also been frustrating. Wellcome's AZT, like other inhibitors of DNA replication, is palliative only, and understandably has damaging sideeffects. The search for drugs which, perhaps in conjunction with AZT, may offer better protection is promising but necessarily slow. It should be within the power of the pharmaceutical industry to improve on the methods of treating the secondary infections to which AIDS patients succumb, but the frequency of Kaposi's sarcoma in some kinds of AIDS patients is not, as yet, understood.

What, in these circumstances, should be our view of the place of AIDS in the modern world? And how should rich countries like ours respond? To say that the outcome of the research of the past ten years has been disappointing does not imply that research should be abandoned. To understand the pathogenesis of AIDS is an even more important goal now than when it was thought there might be a vaccine around the corner.

So too is a better understanding of the way in which the existence of a substantial pool of people with serious immune suppression may contribute to the emergence of virulent forms of other infections, tuberculosis for example. Is there really a connection between AIDS and the emergence in New York of tuberculosis strains immune to BCG, for example? But, at least temporarily, the interests of people with AIDS suggests that there should be a more vigorous attempt to treat the secondary infections, symptoms though they are.

That amounts to acknowledging that AIDS will be among us for some time yet, and that we must learn to live with it as safely as we can. That means that the condom is no longer just a contraceptive, but a medicine. To recognize it as such requires a greater degree of openness about sexual practices than many people find palatable. But there is no choice.

There is also an urgent need to meet head-on the anger now common among the community of AIDS patients, especially in the United States. It is an almost palpable phenomenon. Many carriers of HIV believe they have been given a death sentence by their physicians and hold, however irrationally, that the establishment is bent on doing them down; intravenous drug users and male homosexuals, already persecuted as they see it, are naturally the most prone to share this socially corrosive resentment. Wild advocacy at the outset of the epidemic of quarantine for those infected did not help.

How else to blunt this anger except by making sure that AIDS patients are dealt with sympathetically and civilly, and that they are given the best care that can be afforded? That does not imply that AIDS patients are intrinsically more deserving of care than people with, say, some fatal form of cancer. It is merely that they are the unlucky victims of a common fallacy of just a decade ago, the belief that fatal infections had either been eliminated or would soon be eliminated.

Meanwhile, it is only seemly to record that little headway is likely to be made against the incidence of AIDS, in some of the poorer countries of Africa for example. If there were the funds for diagnostic tests, it might be more prudent to spend them in other ways, to combat intestinal diseases in infancy for example. But if things drag on as they are for another decade, that is what will make us feel badly.

John Maddox

Extracts from a talk at Green College, Oxford, 9 February 1993. 